\title{
Evaluation of a structured skills training group for adolescents with attention-deficit/hyperactivity disorder: a randomised controlled trial
}

\author{
Jenny Meyer ${ }^{1}$ (D) Mia Ramklint ${ }^{1}$ (D) Maria Unenge Hallerbäck ${ }^{2} \cdot$ Måns Lööf $^{3} \cdot$ Johan Isaksson $^{1,4}$ (D)
}

Received: 11 August 2020 / Accepted: 26 February 2021 / Published online: 15 March 2021

(c) The Author(s) 2021

\begin{abstract}
Attention-deficit/hyperactivity disorder (ADHD) in adolescence is associated with behavioural, emotional and interpersonal problems, and non-pharmacological treatments targeting these difficulties have been requested. The objective of this study was to evaluate the effectiveness and acceptance of an age-adapted structured skills training group (SSTG) for adolescents with ADHD. Adolescents ( $n=184$, ages 15-18 years) with a diagnosis of ADHD were randomly assigned to either the SSTG, which is based on dialectical behavioural therapy, or an active control group based on psychoeducation. Symptoms of ADHD, behavioural and emotional problems, functional impairment, and health-related outcomes were assessed with self-ratings and parental ratings two weeks before, two weeks after, and six months after treatment. All participants who completed the pre-treatment measurements $(n=164)$ were included in the main analyses, which were conducted using a linear mixed model. Our results demonstrated no significant group differences in favour of the SSTG for any of the study outcomes. A majority of the participants in both groups reported that they had increased their knowledge about ADHD, improved their ability to manage problems related to the diagnosis, and would recommend the treatment to others. We conclude that the SSTG seems to be acceptable for adolescents with ADHD in a clinical context. However, the treatment was not proved to be more effective or more acceptable than the psychoeducational control intervention.
\end{abstract}

Trial registration: http://www.isrctn.com/ISRCTN17366720,11/05/2016, retrospectively registered.

Keywords Adolescence $\cdot$ ADHD $\cdot$ Cognitive behavioural therapy $\cdot$ Dialectical behavioural therapy $\cdot$ Psychoeducation

\section{Introduction}

Attention-deficit/hyperactivity disorder (ADHD) is characterised by symptoms of inattention, hyperactivity and impulsivity, resulting in functional impairment across several life domains [1]. Specifically, adolescents with ADHD

Johan Isaksson

johan.isaksson@neuro.uu.se

1 Department of Neuroscience, Child and Adolescent Psychiatry Unit, Uppsala University, Akademiska Sjukhuset, 75185 Uppsala, Sweden

2 School of Medical Sciences, Örebro University, Örebro, Sweden

3 Child and Adolescent Psychiatric Clinic, Gävle, Sweden

4 Department of Women's and Children's Health, Karolinska Institute Centre of Neurodevelopmental Disorders (KIND) Centre for Psychiatry Research, Karolinska Institute, Stockholm, Sweden have an increased risk of academic problems, including poor schoolwork completion, school drop-out and academic failure $[2,3]$. Interpersonal problems are also common among youths with ADHD [2,4], who show an impaired ability to effectively participate in social exchange (e.g., more often express anger, have difficulties in communication and turntaking) [5, 6]. In addition, elevated emotion reactivity, emotion regulation difficulties, and psychiatric comorbidity are common problems among adolescents with ADHD [7-9], leading to further psychosocial impairment [6, 7]. Adolescents with ADHD have low ratings on the quality of life, especially in psychosocial domains [10]. Hence, it is imperative to implement effective and acceptable treatments for adolescents with ADHD that target both ADHD symptoms and the associated problems of emotional dysregulation and social skills.

The NICE guidelines [11] recommend a stepwise care model for managing ADHD, with psychoeducation and environmental modifications regarded as first-line interventions. 
While pharmacological treatments have been shown to have an effect on ADHD symptoms [12], psychosocial treatments might be more beneficial for improving adaptive function in everyday life $[11,13]$. Corroborating this, the NICE guidelines [11] recommend cognitive behavioural therapy (CBT), targeting social skills, problem-solving and emotion regulation, for adolescents in whom impairments persist despite medication - preferably in a group setting for cost-effectiveness. Two randomised controlled trials (RCT) have demonstrated promising results of CBT for medicated adolescents with ADHD when compared with a waiting list $[14,15]$, indicating that CBT treatment can reduce ADHD symptoms and functional impairment, at least in the short term. The overall effects of psychosocial treatments for adolescents with ADHD have been summarised in a systematic review by Chan and colleagues [12]. Despite some promising findings on ADHD symptoms and the improvement of skills such as planner use and homework completion, the authors concluded that the effects of psychosocial treatments on ADHD symptoms and functional impairment were inconsistent [12]. Considering the burden of emotional and relational problems among adolescents with ADHD [2-9, 16], interventions for this age group should preferably also focus on emotional dysregulation, psychiatric comorbidity and interpersonal problems $[8,17]$.

A CBT method which explicitly targets emotional dysregulation and relational problems is dialectical behavioural therapy (DBT), where techniques such as mindfulness, acceptance, behavioural analysis, and social skills are practiced continuously [18]. Although originally developed for patients with borderline personality disorder (BPD) [19], DBT-based methods have been proposed to be suitable for patients with ADHD due to the symptom overlap with BPD [20]. Some studies have focused specifically on mindfulness, with an aim of teaching functional skills to self-regulate attention and emotional reactivity. In a recently published meta-analysis, the findings indicated that mindfulness-based treatments could have the potential to decrease ADHD symptoms [21]. However, this meta-analysis did not include any RCTs, meaning that no firm conclusions regarding the effect of mindfulness can be drawn.

Other studies have evaluated a structured skills training group (SSTG), developed for adult patients with ADHD [22]. The SSTG combines traditional CBT with DBT and targets both the core symptoms of ADHD and associated difficulties, such as emotional dysregulation and relational problems. In uncontrolled studies, the SSTG was associated with reductions in ADHD symptoms, comorbidity and functional impairment, and improvement in personal health [22-24]. When using an RCT design with an active control group, the SSTG was found to be superior to a loosely structured discussion group regarding effects on ADHD symptoms and perceived ability to cope with deficits, but not regarding symptoms of comorbidity [25]. In the largest RCT to date, only the blinded clinical global impression ratings supported the SSTG as superior to individual clinical management [26]. These mixed findings indicate that the SSTG could be beneficial for some patients with ADHD, but also underline the impact of study design and choice of control condition. The SSTG has not yet been evaluated regarding its effectiveness for adolescents with ADHD.

To summarise, while a few studies have found promising results of CBT for adolescents with ADHD, the quality of evidence in this research area remains low [11] and there is a lack of studies evaluating group-based DBT for adolescents with ADHD. Thus, the aim of this study was to investigate the effectiveness and acceptance of an age-adapted SSTG based on DBT, for adolescents with ADHD in a clinical setting. We hypothesised that the SSTG would be superior regarding the improvement of symptoms and functioning, compared with a psychoeducational control intervention, and that the SSTG would be acceptable for adolescents with ADHD.

\section{Methods}

\section{Design and procedures}

This was a multi-centre RCT with two study arms comparing the SSTG with a psychoeducational control intervention performed in a clinical context. The methods have previously been described in a study protocol [27]. The recruitment, interventions and data collection were conducted at seven child and adolescent psychiatric (CAP) outpatient units in Sweden (the recruitment procedure is described in greater detail in Supplement S1). The outcome measures were assessed in self-reports and parental reports two weeks before (T1), 2 weeks after (T2) and 6 months after treatment (T3). Recruitment started in 2015 and the last follow-up measures were collected during the spring of 2019. The study was performed and reported in accordance with CONSORT guidelines (see Supplement S2 for CONSORT checklist).

\section{Participants}

Sample characteristics are presented in Table 1 and the participant flow is shown in Fig. 1. The participants were patients aged 15-18 years, with a clinical diagnosis of ADHD according to the International Classification of Disease (ICD-10) [28], which was retrieved from the participants' medical record. Assessment of study eligibility was conducted before randomisation by clinical psychologists who interviewed the adolescents and their parents at the CAP units. Exclusion criteria were severe depression, 
Table 1 Clinical characteristics of the sample

\begin{tabular}{|c|c|c|}
\hline Characteristics & $\begin{array}{l}\text { SSTG } \\
(n=85)\end{array}$ & $\begin{array}{l}\text { Control group } \\
(n=79)\end{array}$ \\
\hline Female, $n(\%)$ & $56(65.8)$ & $49(62.0)$ \\
\hline Mean age, years (SD) & $16.46(0.88)$ & $16.71(0.94)$ \\
\hline \multicolumn{3}{|c|}{ Clinical diagnosis of ADHD (ICD-10), $n(\%)$} \\
\hline Combined & $58(68.2)$ & $58(73.4)$ \\
\hline Inattentive & $24(28.2)$ & $18(22.8)$ \\
\hline ADHD unspecified & $3(3.5)$ & $3(3.8)$ \\
\hline \multicolumn{3}{|c|}{$\begin{array}{l}\text { ADHD presentation (MINI-KID), } n(\%) \text {, mean no of } \\
\text { symptoms }\end{array}$} \\
\hline Combined & 33 (38.8), 15.06 & $40(50.6), 15.10$ \\
\hline Inattentive & $33(38.8), 9.42$ & $25(31.6), 9.40$ \\
\hline Hyperactive-impulsive & $2(2.4), 11.00$ & $1(1.3), 12.00$ \\
\hline Unspecified ADHD ${ }^{a}$ & 17 (20.0), 5.47 & $13(16.5), 5.46$ \\
\hline \multicolumn{3}{|c|}{ Psychiatric comorbid symptoms ${ }^{\mathrm{b}}, n(\%)$} \\
\hline Anxiety & $26(32.1)$ & $26(33.3)$ \\
\hline Depression & $16(19.8)$ & $12(15.4)$ \\
\hline Disruptive behaviour & $33(39.8)$ & $24(30.4)$ \\
\hline At least one comorbidity & $49(62.0)$ & $45(57.7)$ \\
\hline \multicolumn{3}{|l|}{ Functional impairment ${ }^{\mathrm{c}}$, mean (SD) } \\
\hline School & $7.17(2.14)$ & $6.89(2.74)$ \\
\hline Social & $5.95(2.35)$ & $5.44(2.58)$ \\
\hline Home & $5.17(2.93)$ & $4.32(2.89)$ \\
\hline \multicolumn{3}{|l|}{ Medication $^{\mathrm{d}}, n(\%)$} \\
\hline ADHD medications & $60(72.3)$ & $64(81.0)$ \\
\hline Antidepressants \& sedatives & $19(22.9)$ & $16(20.3)$ \\
\hline Sleep medications & $20(24.1)$ & $14(17.7)$ \\
\hline Antipsychotics \& mood stabilizer & $1(1.2)$ & $2(2.5)$ \\
\hline
\end{tabular}

$A D H D$ Attention-deficit/hyperactivity disorder, ICD International Classification of Disease, MINI-KID Mini International Neuropsychiatric Interview for Children and Adolescents, SD standard deviation, SSTG structured skills training group

${ }^{a}$ Unspecified ADHD includes participants who did not fulfill the criteria for any of the main presentations in the MINI-KID interview

${ }^{b}$ Affective comorbidity was assessed using self-ratings $(n=159)$ on the subscales in the Hospital Anxiety and Depression scale. A score of $\geq 10$ points on the subscale of depression was classified as depression and a score of $\geq 12$ points on the subscale of anxiety was classified as anxiety. Disruptive behaviour was identified based on parental ratings $(n=162)$ on the subscale of conduct problems in the Strengths \& Difficulties Questionnaire, where a score of $\geq 4$ was classified as disruptive behaviour. At least one comorbidity was based on the number of participants for whom both self-ratings and parental ratings were available (SSTG: $\mathrm{n}=79$; control group: $\mathrm{n}=78$ )

c Functional impairment was assessed using parental ratings on the Child Sheehan Disability Scale, where each area ranges from 0 to 10 . A score of $1-3=$ little impairment, $4-6=$ moderate impairment and $\geq 7=$ high impairment

d Parental reports of ADHD medication, including methylphenidate, atomoxetine, lisdexamfetamine or guanfacine. Parental reports of other psychopharmacological medication included antidepressants: fluoxetin, sertralin, escitalopram, bupropion; sedatives: prometazin, alimemazin, hydroxizin; sleep medications: melatonine, propiomazin; mood stabilizers: lithium; antipsychotics: olanzapine, aripiprazole, risperidone suicidality, psychosis, or bipolar disorder without stable medication, mental retardation, organic brain injury, autism spectrum disorder or current substance abuse. Any ongoing pharmacological treatment for ADHD should be stable during the treatment and the participants were requested not to take part in any other psychosocial treatment during the study period. The psychologists performed a clinical evaluation of each adolescent's mental health status and investigated the presence of any exclusion criteria. In cases of uncertainty, the psychologist checked current comorbidities in that adolescent's medical record. 


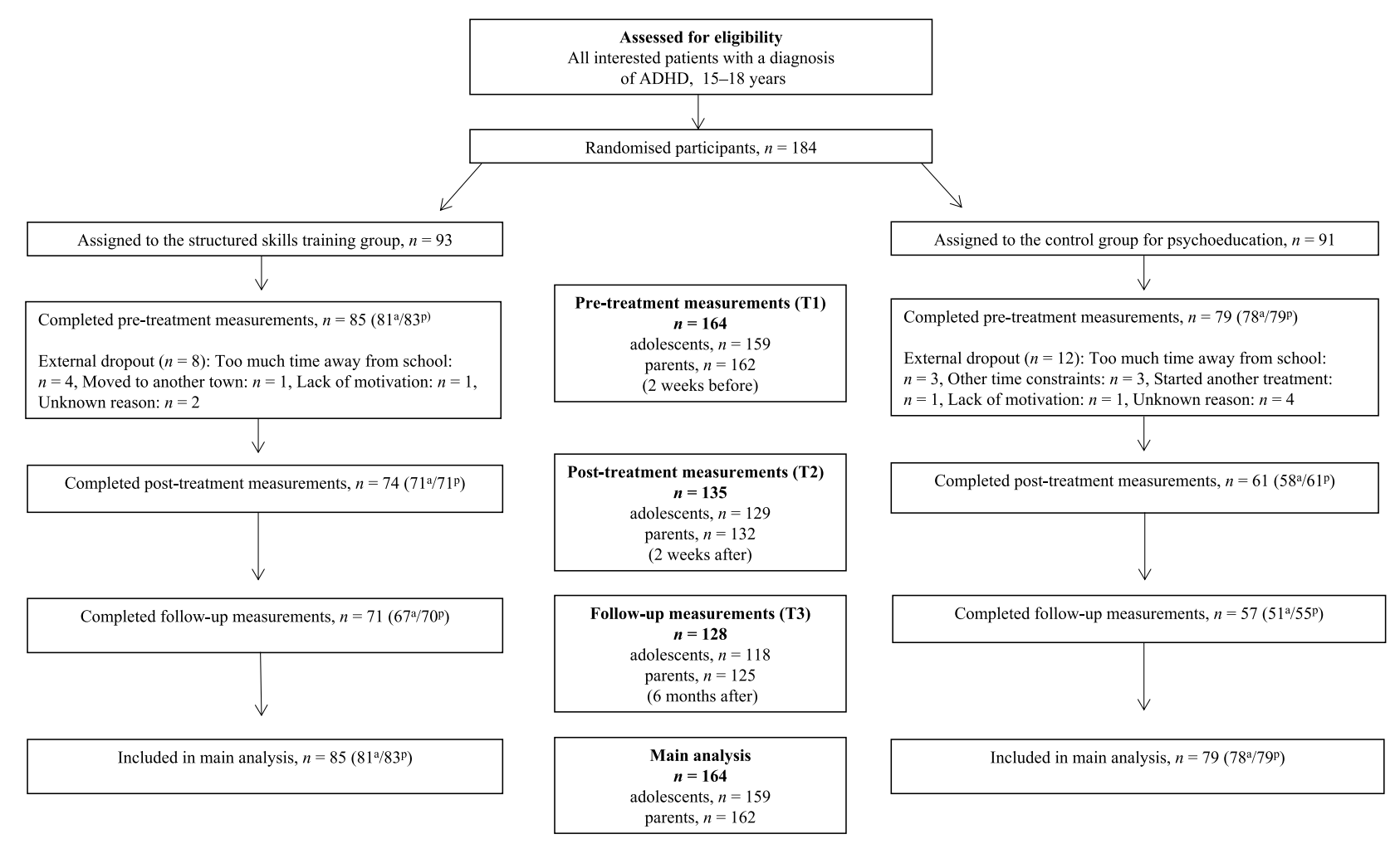

$A D H D$ attention-deficit/hyperactivity disorder

$a$ adolescents, $p$ parents

Fig. 1 Participant flow

Since the adolescents were diagnosed with ADHD prior to the study (in some cases, several years earlier), each participant's current presentation of ADHD symptoms was assessed by clinical psychologists at the CAP units using the section for ADHD in the Mini International Neuropsychiatric Interview for Children and Adolescents (MINI-KID) [29]. The current presentation of symptoms was based on the number of prevalent symptoms in the preceding 6 months and assessed in accordance with the fifth edition of the Diagnostic and Statistical Manual of Mental Disorders (DSM5) [1]. Participants who fulfilled fewer than six symptoms ( $<$ five symptoms for adolescents aged 17 years and older) of both inattention and hyperactivity/impulsivity, were categorised as unspecified ADHD. As shown in Table 1, the participants' current presentations of symptoms revealed a transition in symptomatology, where the predominantly inattentive presentation and unspecified ADHD were more prevalent, according to the MINI-KID assessment, compared with the prior clinical diagnoses. A majority of the participants $(76.5 \%)$ had pharmacological treatment for ADHD when entering the study and more than one-third (35.8\%) had additional psychopharmacological treatment. Overall, the participants had moderate to high levels of functional impairment, and about two-thirds (59.9\%) of the sample reported other psychiatric symptoms that indicated psychiatric comorbidity.

In all, 184 participants were randomised, and 164 participants completed the T1 measurements. Randomised participants who did not complete $\mathrm{T} 1$ were defined as external dropouts and not included in the statistical analyses. Those who completed T1 but did not complete any of the assessments post-treatment were defined as internal dropouts and included in the analyses.

\section{Interventions}

\section{SSTG}

The treatment is an age-adapted version of a manualised DBT-based group programme originally developed for adults with ADHD [30, 31] and consists of 14 weekly 2-h sessions, where each session has a specific theme. For more detailed information about the SSTG, see Supplement S3. SSTG includes elements of psychoeducation and strategies for managing difficulties related to ADHD. DBT elements, such as mindfulness, acceptance, behavioural analysis and 
social skills, are incorporated and practiced during treatment. Age adaptions, such as simplified language, more practical exercises, and less theory, were made prior to treatment initiation [27]. Each group was led by two therapists, who were clinicians working at the CAP units, of which at least one was a psychologist and one was trained in DBT. Minor modifications of the age-adapted SSTG were made after the first treatment period $(n=19)$, but as no significant outcome differences were found between the groups preand post-modification, all SSTG participants were merged into one group. The group leaders registered the attendance and completed homework assignments of each participant ( $\max =13$ assignments).

Psychoeducational control intervention The control group followed a manual-based psychoeducational group programme (SKILLS), designed by JI and ML. The intervention consists of three 2-h sessions, where the main focus is psychoeducation about ADHD, including information about ADHD symptomatology, strengths and challenges with ADHD, sleep and diet, stress management, problem-solving, and structuring daily life routines. For more detailed information about the psychoeducational intervention, see Supplement S3. The participants also received a book describing tools to facilitate schoolwork. Each group was led by two therapists, who were clinicians working at the CAP units. DBT-related components were not included in the control intervention. The group leaders registered the attendance and completed homework assignments of each participant ( $\max =2$ assignments).

Treatment fidelity All therapists (psychologists, psychiatrist, psychiatric nurses and social workers) were trained in the respective method before delivering the intervention. The training included education covering the manual and practical exercises. The manual was also discussed at yearly meetings with the therapists involved in the project. Continuous supervision for each method was offered during the study period, whereby the therapists could receive support and guidance for upcoming sessions, to stay adherent to the method. The training and supervision of the SSTG were provided by a clinical psychologist and psychotherapist, educated in DBT and with experience of the SSTG. Adherence to the SSTG method was assessed by ratings of 27 videorecorded sessions. Two clinical psychologists with expertise in CBT and the SSTG method performed adherence ratings on a five-point scale, ranging from 1 (unacceptable) to 5 (excellent). The average adherence was considered acceptable to $\operatorname{good}(M=3.57, S D=0.34)$; for information about the adherence ratings, see Supplement S4. The training in and supervision of the psychoeducational control intervention was provided by a clinical nurse and psychotherapist, with expertise in the method. The group leaders were care- fully informed to stick strictly to the manual and use the PowerPoint presentation created for each respective session. No formal adherence assessment was performed for the therapists in the control group.

\section{Measurements}

\section{Current medication}

Current ADHD medication was reported by parents at T1, T2 and T3. For this study, reported ADHD medication was categorised as: stable medication (i.e., continued with ADHD medication throughout the study period), major change of medication (i.e., either stopped or started using ADHD medication) or no medication (i.e., did not use any ADHD medication).

\section{Primary outcomes}

ADHD symptoms were assessed using self-ratings and parental ratings on the Adult ADHD Self-Report Scale for Adolescents (ASRS-A) [32, 33]. The questionnaire contains 18 items corresponding to the diagnostic criteria of ADHD, measured on a 5-point scale from 0 (never) to 4 (very often), with higher scores indicating more symptoms. The ASRSA has shown promising psychometric properties in clinical populations [32, 33]. In this study, Cronbach's alpha $(\alpha)$ indicated good to excellent internal consistency ( $\alpha=0.91$ for self-ratings and $\alpha=0.89$ for parental ratings).

Functional impairment was assessed using self-ratings and parental ratings on the Child Sheehan Disability Scale (CSDS) [34]. The self-rating scale assesses functional impairment in three areas (school, social activities, and home). The parental rating scale assesses the impact of the adolescents' symptoms in five areas (school, social activities, home, parents' work, and parents' social activities). The impairment in each area is measured on an 11-point scale from 0 (not at all) to 10 (very much), with higher scores indicating more impairment. The CSDS has shown good validity in a sample of children and adolescents with psychiatric disorders [34] and displayed acceptable to good internal consistency ( $\alpha=0.77$ for self-ratings and $\alpha=0.83$ for parental ratings) in this study.

The impact of ADHD-related symptoms on each adolescent's wellbeing was measured using the questionnaire Impact of ADHD Symptoms (IAS), constructed for this study. IAS is a six-item self-rating scale where the adolescent indicates the extent to which their wellbeing during the preceding week has been affected by impulsive behaviours, difficulties starting and completing assignments on time, hyperactivity, sleep problems, emotional dysregulation and stress. Each item is answered on an 11-point scale from 0 (not at all) to 10 (very much), with higher scores indicating 
a greater impact of symptoms. IAS displayed good internal consistency $(\alpha=0.80)$ in this study.

Quality of life was measured using the Global Quality of Life scale $(G Q L)$ [35]. The adolescents answered the question "How is your life right now?" on an 11-point scale from 0 (the worst imaginable life situation) to 10 (the best imaginable life situation). The GQL has shown acceptable psychometric properties in a clinical sample of adults with psychiatric disorders [35].

Mindfulness was measured using the Five Facet Mindfulness Questionnaire (FFMQ) [36, 37], with 29 items measured on a 5-point self-rating scale from 1 (never/almost never) to 5 (always), where higher scores reflect a higher level of mindfulness. The construct validity of the scale is supported $[36,37]$ and the internal consistency for the total scale was acceptable $(\alpha=0.77)$ in this study.

\section{Secondary outcomes}

Total difficulties of behavioural and emotional problems were assessed using self-ratings and parental ratings, based on the total difficulty score from the Strengths \& Difficulties Questionnaire (SDQ) [38]. The score encompasses 20 statements about the occurrence of ADHD symptoms and emotional, conduct and peer problems, measured on a 3 -point scale from 0 (not true) to 2 (certainly true), where higher scores indicate more severe problems. The Swedish version of the SDQ has shown adequate validity [39] and an acceptable internal consistency was observed in this study ( $\alpha=0.78$ for self-ratings and $\alpha=0.72$ for parental ratings). In the descriptive statistics, the parent-rated subscale of conduct problems was used to identify patients with elevated disruptive behaviours, using the cut-off value suggested by previous research [40].

Symptoms of anxiety and depression were measured using self-ratings on the Hospital Anxiety and Depression Scale (HADS) [41]. The questionnaire contains 14 statements measured on a 4-point scale, ranging from 0 to 3 , where higher scores indicate a greater occurrence of symptoms. The HADS has shown good psychometric properties in a sample of adolescents [42] and the internal consistency was good in this study $(\alpha=0.85)$. In the descriptive statistics, the subscales of depression and anxiety were used to identify patients reporting clinical levels of symptoms of these respective conditions, using the cut-off values suggested by previous research [42].

Perceived stress was measured using self-ratings on the Pressure Activation Stress scale (PAS) [43]. The questionnaire consists of 11 items, measuring stress symptoms on a 5-point scale from 0 (never) to 4 (always), where higher scores indicate more stress. The scale has displayed a promising face validity and good internal consistency [43], which was confirmed in this study $(\alpha=0.88)$.
Sleep problems were measured using self-ratings on the Karolinska Sleep Questionnaire (KSQ) [44]. The KSQ includes seven statements about difficulties falling asleep and waking up. Each item is measured on a 6-point scale from 0 (never) to 5 (always), where higher scores indicate more sleep problems. The KSQ has shown adequate psychometric properties [44] and the internal consistency was good in this study $(\alpha=0.83)$.

\section{Treatment acceptability}

After the final group session, the participants answered a questionnaire about how they had perceived and responded to the group intervention. The questionnaire was inspired by a questionnaire from the Swedish SSTG manual for adults [31], which was adapted and shortened by the research team to be used for adolescents, and included four questions about if their knowledge about ADHD had increased, if they were more able to manage problems related to ADHD, how much they had benefitted from the treatment, and if they would recommend it to others.

\section{Randomisation}

Participants were randomised to one of the two treatment conditions using a computer-generated allocation sequence (https://www.randomizer.org) with separate sequence lists for each treatment centre, where the participants were randomly assigned at a 1:1 ratio. Codes were used to ensure information confidentiality and participant anonymity and the principal investigator performed treatment allocation based on the codes. Participants were not blinded to the treatment condition.

\section{Statistical analyses}

The appropriate sample size was determined based on a power calculation to detect a group difference of at least seven points on the ASRS-A and a difference of at least four points on the CSDS. Specifically, to obtain a moderate effect size $(\mathrm{d} \geq 0.50)$ with a power of $80 \%$, using a two-tailed t-test, $\alpha=0.05$, the final sample size had to be at least 100 participants (a detailed description of the power calculation is provided in the study protocol) [27]. All analyses were conducted with the Statistical Package for the Social Sciences (IBM SPSS), version 26. Normal distribution was explored for each group separately, and after adjusting for single outliers by changing the outlier to the nearest value $(n=1$ on two scales and $n=2$ on one scale), all the scales were regarded as normally distributed, i.e., the values of $Z_{\text {Skewness }}$ and $Z_{\text {Kurtosis }}$ were in the range of -1.96-1.96 [45]. Descriptive statistics were used to describe the sample. Attrition analyses and differences between the two groups regarding 
baseline variables, medication, attendance and homework completion were assessed using independent-samples t-tests and chi-squared tests. Treatment outcomes were compared between the different treatment sites, using one-way analysis of variance (ANOVA) with Tukeys' HSD as a post hoc test.

The main analysis from the published study protocol [27] was changed from a general linear model to a linear mixed model because of the mixed model's advantages of using all available data from participants and enabling inclusion of random effects [46]. Multiple imputation of missing data was not used. In the linear mixed model, a major change in medication (i.e., stopped or started ADHD medication) was used as a covariate, the participants' baseline values as random intercept, time and treatments as fixed factors, and time by treatment as an interaction term. The effectiveness of the treatment was estimated by contrasting the longitudinal mean changes between the SSTG and the control group at each timepoint. Specifically, the change in symptoms from $\mathrm{T} 1$ to $\mathrm{T} 2$ and the change from $\mathrm{T} 1$ to $\mathrm{T} 3$ were compared separately. Within-group differences were explored by calculating the mean changes within each group between each timepoint. A sensitivity analysis was conducted on the completers, i.e., those who attended at least two-thirds of the sessions (SSTG, $n=54$; control group, $n=62$ ). In addition, a sensitivity analysis was conducted for the IAS item regarding the impact of emotional dysregulation, to investigate group differences and within-group changes in this specific outcome. Cohen's d was used as a measure of effect size, using the observed values for each group. Treatment acceptability was investigated using descriptive statistics for each group. As a supplementary analysis, group differences regarding acceptability were explored using the chi-squared test. All the reported results were considered significant at the $5 \%$ level.

\section{Results}

\section{Sample characteristics}

No significant differences were found between the two groups at baseline. Moreover, the attrition analysis showed no differences in the baseline values between the internal dropouts and those who completed post-measurements. No group differences were found in regard to patterns/changes in ADHD medication during the study. More specifically, a majority in both groups had a stable medication during the study (62\% in the SSTG and $72 \%$ in the control group), nearly one fifth underwent a major change in medication (21\% in the SSTG and $18 \%$ in the control group) and somewhat fewer had no ADHD medication throughout the study (17\% in the SSTG and $10 \%$ in the control group). The mean attendance in the SSTG was 8.7 sessions $(62 \%$ of all included sessions), while the mean attendance in the control group was 2.3 sessions (76\% of all included sessions), revealing a significant group difference in the proportion of attendance $(t=2.76, p=0.007)$. Although a substantial proportion of data was missing regarding homework completion, the available data $(\mathrm{n}=93)$ indicated no group difference. More specifically, $45 \%$ of the homework assignment were completed in the SSTG, while $43 \%$ of the homework assignments were completed in the control group. No differences in the treatment outcomes were found between the treatment sites.

\section{Primary outcomes}

Between- and within-group differences are presented in Table 2. No differences were observed between the two groups regarding changes in the primary outcomes (effect sizes indicated no to small effects, $d=0.01$ to 0.33 ). Withingroup changes were found in the SSTG, with reductions of ADHD symptoms and functional impairment in both selfreports (T1-T3) and parental reports (T1-T2 and T1-T3). These results were confirmed in the sensitivity analysis of completers. For the control group, only parents reported reductions of ADHD symptoms and functional impairment (T1-T3), and the sensitivity analysis of completers showed a reduction of parentally rated ADHD symptoms at T2 as well. Cohen's d indicated moderate effects for the decrease of ADHD symptoms in the SSTG according to parental reports $(d=0.59$ [T1-T2], $d=0.62$ [T1-T3]) and small effects for the other significant within-group differences $(d=0.26-0.45)$. The sensitivity analysis regarding the impact of emotional dysregulation revealed neither group differences nor within-group changes.

\section{Secondary outcomes}

Between- and within-group differences are presented in Table 3. No differences were observed between the two groups regarding changes in total difficulties, symptoms of depression and anxiety, or perceived stress (effect sizes indicated no to small effects, $d=0.09$ to 0.36 ). One between-group difference was found regarding sleep problems, in favour of the control group. This difference was only observable at $\mathrm{T} 2$ and was neither preserved at T3 nor confirmed in the sensitivity analysis of completers. No within-group differences in sleep problems were found in either of the groups. Regarding self-reported symptoms of anxiety and depression, a within-group difference was found for the SSTG (T1-T3). In the sensitivity analysis, this was attenuated to a trend $(B=1.42$, $p=0.064)$. Within-group differences of total difficulties were observed for both groups, indicating a decrease of emotional and behavioural difficulties. These results were 
Table 2 Primary outcomes with Estimated Marginal Means (EMM) and 95\% Confidence Interval (CI) obtained from the linear mixed model; adjusted for changes in medication

\begin{tabular}{|c|c|c|c|c|c|c|}
\hline Variable & $\begin{array}{l}\text { Baseline (T1) } \\
E M M(C I)\end{array}$ & $\begin{array}{l}\text { Post (T2) } \\
E M M(C I)\end{array}$ & $\begin{array}{l}\text { Follow-up (T3) } \\
E M M(C I)\end{array}$ & T1-T2; $B(C I)$ & $\mathrm{T} 1-\mathrm{T} 3 ; B(C I)$ & $\begin{array}{l}\text { Time by group } \\
\text { interaction } \\
\mathrm{T} 1-\mathrm{T} 2 ; B(C I) \\
\mathrm{T} 1-\mathrm{T} 3 ; B(C I)\end{array}$ \\
\hline \multicolumn{7}{|c|}{$\begin{array}{l}\text { ADHD-symptoms } \\
\text { (adolescent) }\end{array}$} \\
\hline SSTG & $\begin{array}{l}40.05 \\
\quad(36.57 ; 43.52)\end{array}$ & $\begin{array}{l}38.97 \\
\quad(35.47 ; 42.47)\end{array}$ & $\begin{array}{l}36.89 \\
\quad(33.37 ; 40.41)\end{array}$ & $\begin{array}{l}1.08 \\
\quad(-1.08 ; 3.23)\end{array}$ & $\begin{array}{l}3.16 \\
\quad(0.97 ; 5.35)^{*}\end{array}$ & $\begin{array}{l}-0.95 \\
\quad(-4.13 ; 2.23)\end{array}$ \\
\hline Control group & $\begin{array}{l}43.72 \\
\quad(39.90 ; 47.55)\end{array}$ & $\begin{array}{l}43.60 \\
\quad(39.76 ; 47.44)\end{array}$ & $\begin{array}{l}43.59 \\
\quad(39.66 ; 47.52)\end{array}$ & $\begin{array}{l}0.13 \\
\quad(-2.21 ; 2.46)\end{array}$ & $\begin{array}{l}0.14 \\
\quad(-2.35 ; 2.63)\end{array}$ & $\begin{array}{l}-3.02 \\
\quad(-6.34 ; 0.30)\end{array}$ \\
\hline \multicolumn{7}{|c|}{$\begin{array}{l}\text { ADHD-symptoms } \\
\text { (parent) }\end{array}$} \\
\hline SSTG & $\begin{array}{l}44.37 \\
\quad(41.44 ; 47.31)\end{array}$ & $\begin{array}{l}39.77 \\
\quad(36.84 ; 42.71)\end{array}$ & $\begin{array}{l}38.03 \\
\quad(35.08 ; 40.98)\end{array}$ & $\begin{array}{l}4.60 \\
\quad(2.61 ; 6.58)^{* * *}\end{array}$ & $\begin{array}{l}6.34 \\
\quad(4.33 ; 8.36)^{* * *}\end{array}$ & $\begin{array}{l}-2.73 \\
\quad(-5.65 ; 0.19)\end{array}$ \\
\hline Control group & $\begin{array}{l}41.79 \\
\quad(38.58 ; 45.00)\end{array}$ & $\begin{array}{l}39.92 \\
\quad(36.71 ; 43.13)\end{array}$ & $\begin{array}{l}37.94 \\
\quad(34.67 ; 41.21)\end{array}$ & $\begin{array}{l}1.87 \\
\quad(-0.27 ; 4.01)\end{array}$ & $\begin{array}{l}3.85 \\
\quad(1.61 ; 6.09)^{* * *}\end{array}$ & $\begin{aligned}- & 2.50 \\
& (-5.51 ; 0.52)\end{aligned}$ \\
\hline \multicolumn{7}{|c|}{$\begin{array}{l}\text { Functional impair- } \\
\text { ment (adoles- } \\
\text { cent) }\end{array}$} \\
\hline SSTG & $\begin{array}{l}13.85 \\
\quad(12.03 ; 15.67)\end{array}$ & $\begin{array}{l}12.34 \\
\quad(10.50 ; 14.19)\end{array}$ & $\begin{array}{l}11.30 \\
\quad(9.44 ; 13.16)\end{array}$ & $\begin{array}{l}1.51 \\
\quad(-0.07 ; 3.09)\end{array}$ & $\begin{array}{l}2.55 \\
\quad(0.95 ; 4.16)^{* *}\end{array}$ & $\begin{array}{l}-1.09 \\
\quad(-3.42 ; 1.24)\end{array}$ \\
\hline Control group & $\begin{array}{l}14.64 \\
\quad(12.65 ; 16.64)\end{array}$ & $\begin{array}{l}14.22 \\
\quad(12.21 ; 16.24)\end{array}$ & $\begin{array}{l}13.37 \\
\quad(11.27 ; 15.47)\end{array}$ & $\begin{array}{l}0.42 \\
\quad(-1.29 ; 2.13)\end{array}$ & $\begin{array}{l}1.28 \\
(-0.54 ; 3.10)\end{array}$ & $\begin{array}{l}-1.28 \\
\quad(-3.70 ; 1.15)\end{array}$ \\
\hline \multicolumn{7}{|c|}{$\begin{array}{l}\text { Functional impair- } \\
\text { ment (parent) }\end{array}$} \\
\hline SSTG & $\begin{array}{l}26.52 \\
\quad(23.67 ; 29.36)\end{array}$ & $\begin{array}{l}22.94 \\
\quad(20.09 ; 25.78)\end{array}$ & $\begin{array}{l}23.56 \\
\quad(20.70 ; 26.43)\end{array}$ & $\begin{array}{l}3.58 \\
\quad(1.65 ; 5.51)^{* * *}\end{array}$ & $\begin{array}{l}2.95 \\
\quad(0.99 ; 4.91)^{* *}\end{array}$ & $\begin{array}{l}-2.07 \\
\quad(-4.91 ; 0.77)\end{array}$ \\
\hline Control group & $\begin{array}{l}24.88 \\
\quad(21.77 ; 28.00)\end{array}$ & $\begin{array}{l}23.37 \\
\quad(20.26 ; 26.48)\end{array}$ & $\begin{array}{l}21.39 \\
\quad(18.21 ; 24.56)\end{array}$ & $\begin{array}{l}1.51 \\
(-0.57 ; 3.59)\end{array}$ & $\begin{array}{l}3.49 \\
\quad(1.31 ; 5.66)^{* *}\end{array}$ & $\begin{array}{l}0.54 \\
\quad(-2.39 ; 3.47)\end{array}$ \\
\hline \multicolumn{7}{|c|}{$\begin{array}{l}\text { Impact of ADHD- } \\
\text { symptoms }\end{array}$} \\
\hline SSTG & $\begin{array}{l}29.61 \\
\quad(26.21 ; 33.02)\end{array}$ & $\begin{array}{l}27.60 \\
\quad(24.15 ; 31.04)\end{array}$ & $\begin{array}{l}27.57 \\
\quad(24.10 .31 .04)\end{array}$ & $\begin{array}{l}2.02 \\
\quad(-0.62 ; 4.65)\end{array}$ & $\begin{array}{l}2.04 \\
\quad(-0.64 ; 4.72)\end{array}$ & $\begin{array}{l}-2.05 \\
\quad(-5.92 ; 1.83)\end{array}$ \\
\hline Control group & $\begin{array}{l}30.87 \\
\quad(27.13 ; 34.61)\end{array}$ & $\begin{array}{l}30.90 \\
\quad(27.15 ; 34.65)\end{array}$ & $\begin{array}{l}30.59 \\
\quad(26.69 ; 34.48)\end{array}$ & $\begin{array}{l}-0.03 \\
\quad(-2.87 ; 2.81)\end{array}$ & $\begin{array}{l}0.28 \\
\quad(-2.76 ; 3.32)\end{array}$ & $\begin{array}{l}-1.76 \\
\quad(-5.81 ; 2.29)\end{array}$ \\
\hline \multicolumn{7}{|l|}{ Quality of life } \\
\hline SSTG & $\begin{array}{l}5.94 \\
\quad(5.38 ; 6.51)\end{array}$ & $\begin{array}{l}6.01 \\
\quad(5.44 ; 6.59)\end{array}$ & $\begin{array}{l}6.05 \\
\quad(5.46 ; 6.63)\end{array}$ & $\begin{array}{l}-0.07 \\
\quad(-0.61 ; 0.47)\end{array}$ & $\begin{array}{l}-0.10 \\
\quad(-0.65 ; 0.45)\end{array}$ & $\begin{array}{l}-0.09 \\
\quad(-0.89 ; 0.70)\end{array}$ \\
\hline Control group & $\begin{array}{l}5.82 \\
\quad(5.20 ; 6.44)\end{array}$ & $\begin{array}{l}5.99 \\
\quad(5.36 ; 6.61)\end{array}$ & $\begin{array}{l}6.13 \\
\quad(5.47 ; 6.79)\end{array}$ & $\begin{array}{l}-0.17 \\
\quad(-0.75 ; 0.42)\end{array}$ & $\begin{array}{l}-0.31 \\
\quad(-0.94 ; 0.31)\end{array}$ & $\begin{array}{l}-0.20 \\
\quad(-1.04 ; 0.62)\end{array}$ \\
\hline \multicolumn{7}{|l|}{ Mindfulness } \\
\hline SSTG & $\begin{array}{l}85.57 \\
\quad(82.52 ; 88.61)\end{array}$ & $\begin{array}{l}85.36 \\
\quad(82.28 ; 88.44)\end{array}$ & $\begin{array}{l}84.21 \\
\quad(81.11 ; 87.31)\end{array}$ & $\begin{array}{l}0.21 \\
\quad(-2.05 ; 2.47)\end{array}$ & $\begin{array}{l}1.36 \\
(-0.93 ; 3.65)\end{array}$ & $\begin{array}{l}-0.86 \\
\quad(-4.20 ; 2.48)\end{array}$ \\
\hline Control group & $\begin{array}{l}80.62 \\
\quad(77.27 ; 83.97)\end{array}$ & $\begin{array}{l}81.27 \\
\quad(77.89 ; 84.65)\end{array}$ & $\begin{array}{l}80.57 \\
\quad(77.10 ; 84.05)\end{array}$ & $\begin{array}{l}-0.65 \\
\quad(-3.12 ; 1.81)\end{array}$ & $\begin{array}{l}0.05 \\
\quad(-2.56 ; 2.65)\end{array}$ & $\begin{aligned}- & 3.31 \\
& (-4.78 ; 2.15)\end{aligned}$ \\
\hline
\end{tabular}

ADHD Attention-deficit/hyperactivity disorder, SSTG structured skills training group; * $p<0.05 ; * * p<0.01 ; * * * p<0.001$

preserved in the sensitivity analysis. The decrease of total difficulties reported by parents in the SSTG indicated moderate effects $(d=0.68$ [T1-T2], $d=0.69$ [T1-T3]), while the other significant within-group differences indicated small effects $(d=0.25-0.46)$.

\section{Treatment acceptability}

Treatment acceptability is presented in Table 4. A majority of the responding adolescents in both groups reported increased knowledge about ADHD and increased ability to manage ADHD-related problems. Most participants reported having benefited from the group intervention and 
Table 3 Secondary outcomes with Estimated Marginal Means (EMM) and 95\% Confidence Interval (CI) obtained from the linear mixed model; adjusted for changes in medication

\begin{tabular}{|c|c|c|c|c|c|c|}
\hline Variable & $\begin{array}{l}\text { Baseline (T1) } \\
E M M(C I)\end{array}$ & $\begin{array}{l}\text { Post (T2) } \\
E M M(C I)\end{array}$ & $\begin{array}{l}\text { Follow-up (T3) } \\
E M M(C I)\end{array}$ & $\begin{array}{l}\mathrm{T} 1-\mathrm{T} 2 \\
B(C I)\end{array}$ & $\begin{array}{l}\mathrm{T} 1-\mathrm{T} 3 \\
B(C I)\end{array}$ & $\begin{array}{l}\text { Time by group } \\
\text { interaction } \\
\text { T1-T2; } B(C I) \\
\text { T1-T3; } B(C I)\end{array}$ \\
\hline \multicolumn{7}{|l|}{$\begin{array}{l}\text { Total difficulties } \\
\text { (adolescent) }\end{array}$} \\
\hline SSTG & $\begin{array}{l}16.54 \\
\quad(15.10 ; 17.99)\end{array}$ & $\begin{array}{l}15.87 \\
\quad(14.41 ; 17.33)\end{array}$ & $\begin{array}{l}14.96 \\
\quad(13.49 ; 16.43)\end{array}$ & $\begin{array}{l}0.67 \\
\quad(-0.39 ; 1.72)\end{array}$ & $\begin{array}{l}1.58 \\
(0.51 ; 2.65)^{* *}\end{array}$ & $\begin{array}{l}-0.81 \\
\quad(-2.36 ; 0.75)\end{array}$ \\
\hline Control group & $\begin{array}{l}18.17 \\
\quad(16.58 ; 19.76)\end{array}$ & $\begin{array}{l}18.31 \\
\quad(16.71 ; 19.91)\end{array}$ & $\begin{array}{l}16.07 \\
\quad(14.42 ; 17.72)\end{array}$ & $\begin{array}{l}-0.14 \\
\quad(-1.28 ; 1.00)\end{array}$ & $\begin{array}{l}2.10 \\
\quad(0.89 ; 3.31)^{* * *}\end{array}$ & $\begin{array}{l}0.52 . \\
\quad(-1.10 ; 2.14)\end{array}$ \\
\hline \multicolumn{7}{|c|}{$\begin{array}{l}\text { Total difficulties } \\
\text { (parent) }\end{array}$} \\
\hline SSTG & $\begin{array}{l}17.71 \\
\quad(16.35 ; 19.07)\end{array}$ & $\begin{array}{l}14.81 \\
\qquad(13.45 ; 16.17)\end{array}$ & $\begin{array}{l}14.30 \\
(12.93 ; 15.67)\end{array}$ & $\begin{array}{l}2.90 \\
\quad(1.77 ; 4.02)^{* * *}\end{array}$ & $\begin{array}{l}3.41 \\
\quad(2.27 ; 4.55)^{* * *}\end{array}$ & $\begin{array}{l}-0.97 \\
\quad(-2.63 ; 0.68)\end{array}$ \\
\hline Control group & $\begin{array}{l}16.85 \\
\quad(15.36 ; 18.33)\end{array}$ & $\begin{array}{l}14.92 \\
\quad(13.44 ; 16.41)\end{array}$ & $\begin{array}{l}14.33 \\
\quad(12.80 ; 15.85)\end{array}$ & $\begin{array}{l}1.93 \\
(0.71 ; 3.14)^{* *}\end{array}$ & $\begin{array}{l}2.52 \\
\quad(1.26 ; 3.79)^{* * * *}\end{array}$ & $\begin{array}{l}-0.89 \\
\quad(-2.59 ; 0.82)\end{array}$ \\
\hline \multicolumn{7}{|l|}{$\begin{array}{l}\text { Symptoms of } \\
\text { depression \& } \\
\text { anxiety }\end{array}$} \\
\hline SSTG & $\begin{array}{l}15.29 \\
(13.45 ; 17.12)\end{array}$ & $\begin{array}{l}14.7 \\
\quad(12.89 ; 16.59)\end{array}$ & $\begin{array}{l}13.67 \\
\quad(11.81 ; 15.54)\end{array}$ & $\begin{array}{l}0.55 \\
\quad(-0.76 ; 1.86)\end{array}$ & $\begin{array}{l}1.61 \\
\quad(0.28 ; 2.94)^{*}\end{array}$ & $\begin{array}{l}-0.36 \\
\quad(-2.29 ; 1.57)\end{array}$ \\
\hline Control group & $\begin{array}{l}16.61 \\
(14.59 ; 18.62)\end{array}$ & $\begin{array}{l}16.42 \\
\quad(14.39 ; 18.44)\end{array}$ & $\begin{array}{l}15.99 \\
(13.90 ; 18.08)\end{array}$ & $\begin{array}{l}0.19 \\
\quad(-1.23 ; 1.61)\end{array}$ & $\begin{array}{l}0.62 \\
\quad(-0.89 ; 2.13)\end{array}$ & $\begin{array}{l}-1.00 \\
\quad(-3.01 ; 1.02)\end{array}$ \\
\hline \multicolumn{7}{|l|}{ Sleep problems } \\
\hline SSTG & $\begin{array}{l}16.98 \\
\quad(15.07 ; 18.88)\end{array}$ & $\begin{array}{l}18.08 \\
\quad(16.15 ; 20.00)\end{array}$ & $\begin{array}{l}17.92 \\
\quad(15.98 ; 19.87)\end{array}$ & $\begin{array}{l}-1.10 \\
\quad(-2.59 ; 0.38)\end{array}$ & $\begin{array}{l}-0.95 \\
\quad(-2.46 ; 0.55)\end{array}$ & $\begin{array}{l}2.34 \\
\quad(0.15 ; 4.53)^{*}\end{array}$ \\
\hline Control group & $\begin{array}{l}16.66 \\
(14.56 ; 18.75)\end{array}$ & $\begin{array}{l}15.42 \\
\quad(13.31 ; 17.53)\end{array}$ & $\begin{array}{l}16.37 \\
(14.19 ; 18.56)\end{array}$ & $\begin{array}{l}1.24 \\
\quad(-0.37 ; 2.85)\end{array}$ & $\begin{array}{l}0.28 \\
\quad(-1.43 ; 1.99)\end{array}$ & $\begin{array}{l}1.24 \\
\quad(-1.04 ; 3.52)\end{array}$ \\
\hline \multicolumn{7}{|l|}{ Perceived stress } \\
\hline SSTG & $\begin{array}{l}22.54 \\
\quad(20.36 ; 24.72)\end{array}$ & $\begin{array}{l}22.93 \\
(20.73 ; 25.14)\end{array}$ & $\begin{array}{l}22.14 \\
\quad(19.92 ; 24.36)\end{array}$ & $\begin{array}{l}-0.39 \\
\quad(-2.07 ; 1.29)\end{array}$ & $\begin{array}{l}0.40 \\
\quad(-1.13 ; 2.11)\end{array}$ & $\begin{array}{l}-0.26 \\
\quad(-2.74 ; 2.22)\end{array}$ \\
\hline Control group & $\begin{array}{l}24.95 \\
\quad(22.56 ; 27.35)\end{array}$ & $\begin{array}{l}25.60 \\
\quad(23.19 ; 28.01)\end{array}$ & $\begin{array}{l}24.15 \\
\quad(21.66 ; 26.65)\end{array}$ & $\begin{array}{l}-0.65 \\
\quad(-2.48 ; 1.17)\end{array}$ & $\begin{array}{l}0.80 \\
\quad(-1.14 ; 2.74)\end{array}$ & $\begin{array}{l}0.40 \\
\quad(-2.19 ; 2.99)\end{array}$ \\
\hline
\end{tabular}

SSTG structured skills training group; * $p<0.05 ; * * p<0.01 ; * * * p<0.001$

would recommend it to others. The supplementary analysis revealed no significant group differences regarding acceptability.

\section{Discussion}

This is the first RCT evaluating the effectiveness of a DBTbased structured skills training group for adolescents with ADHD, using an active control group based on psychoeducation. No group differences in favour of the SSTG were observed in any of the study outcomes. A majority of the participants in both groups reported that they had increased their knowledge about ADHD and improved their ability to manage problems related to the diagnosis.
Our hypothesis of the SSTG being superior to the psychoeducational control intervention was not supported. Indeed, the only significant group difference that was observed was in regard to sleep problems and was in favour of the control group. However, the absence of a within-group difference in both groups indicates that neither of the interventions had any effect on sleep problems. The lack of group differences in our study is partly in line with the results from previous studies using an active control group [25, 26, 47] and the small effect sizes found in our study corroborate previous literature comparing active interventions [48]. Previously reported group differences have been more prominent in RCTs using non-active control groups, such as a waiting list $[14,15]$. The use of an active control group may decrease the risk of confounders from common factors, e.g., attention 
Table 4 Acceptance ratings

\begin{tabular}{|c|c|c|c|c|c|}
\hline \multicolumn{6}{|l|}{ Item } \\
\hline My knowledge about ADHD has increased ${ }^{\text {a }}$ & Not true & Somewhat true & Certainly true & & \\
\hline SSTG, $n=55$ & $7.3 \%$ & $60.0 \%$ & $32.7 \%$ & & \\
\hline Control group, $n=55$ & $7.3 \%$ & $60.0 \%$ & $32.7 \%$ & & \\
\hline I am more able to manage problems related to $\mathrm{ADHD}^{\mathrm{a}}$ & Not true & Somewhat true & Certainly true & & \\
\hline SSTG, $n=55$ & $10.9 \%$ & $69.1 \%$ & $20.0 \%$ & & \\
\hline Control group, $n=50$ & $16.0 \%$ & $74.0 \%$ & $10.0 \%$ & & \\
\hline Would you recommend others to participate in this group? & Yes & No & & & \\
\hline SSTG, $n=58$ & $87.9 \%$ & $12.1 \%$ & & & \\
\hline Control group, $n=59$ & $89.8 \%$ & $10.2 \%$ & & & \\
\hline How much of a benefit do you think the treatment had for you? & $0=$ no benefit & 1 & 2 & 3 & $\begin{array}{c}4=\text { very } \\
\text { great } \\
\text { benefit }\end{array}$ \\
\hline SSTG, $n=59$ & $5.1 \%$ & $6.8 \%$ & $25.4 \%$ & $44.1 \%$ & $18.6 \%$ \\
\hline Control group, $n=61$ & $6.5 \%$ & $11.5 \%$ & $27.9 \%$ & $42.6 \%$ & $11.5 \%$ \\
\hline
\end{tabular}

ADHD Attention-deficit/hyperactivity disorder, $S S T G$ structured skills training group

a The answer "I don't know" ( $n=5$ for SSTG and $n=6$ and $n=9$ for the control group in the respective cases) was regarded as missing data and excluded from the analysis

from a therapist and being in a group, and enables the drawing of conclusions regarding the effect of one treatment relative to another. However, the design makes it difficult to draw conclusions about the absolute effects of each intervention [49], and the lack of group differences in this study has several possible explanations that need to be discussed.

First, the relatively low attendance and homework completion levels in the SSTG indicate that many of the participants did not receive the entire treatment programme. Even though the analyses of completers confirmed the lack of group differences, we cannot rule out that we would have yield other results if the majority of participants had attended all sessions and performed the homework as intended. The group format prevents the participants from catching up on missed sessions and has somewhat limited flexibility for individual adaption. The addition of individual sessions in parallel with the group sessions [18] could enable both compensation for missed content and create more room for tailoring the practice for individual needs [50]. Second, the SSTG includes several themes, with new concepts and skills introduced over a relatively brief period of time. Accordingly, more extensive practice, including recurrent performance feedback on each skill, might be needed to enable behavioural changes [51]. Moreover, the involvement of parents and teachers in the treatment could be warranted, to support the adolescents' practice and use of the skills in their everyday life [50]. For example, the addition of parental training could strengthen communication and collaboration to improve self-management [12]. Third, motivational interviewing has been included in CBT for adolescents with ADHD [14, 15] and might increase their motivation and adherence to the treatment [12]. Fourth, the study population was heterogenous in regard to symptom burden, comorbidity and functional impairment. Considering the focus of the SSTG, it is possible that a more homogenous study population, e.g., only patients with pronounced problems of emotional dysregulation and interpersonal problems, would have yielded other results.

Both the SSTG and the psychoeducational control intervention were perceived as beneficial by a majority of the participants, who reported increased knowledge about ADHD and an improved ability to manage difficulties related to the diagnosis. In addition, both groups demonstrated significant decreases of ADHD symptoms, functional impairment, and behavioural and emotional problems, which were preserved six months after the treatment. Although the within-group changes could be a result of maturation or regression to the mean, we cannot rule out that both interventions had some effect. Possibly, psychoeducation (which was included in both groups) may have produced more benefits than anticipated when designing the study. Psychoeducation has recently been proposed to result in symptom relief for patients with ADHD [52].

This study has some limitations that need to be addressed. Since the randomisation was performed before the pre-treatment measures there was some dropout between randomisation and T1. This could have introduced a bias of selective drop-out and increased the risk of systematic differences between the groups. However, no group differences were found in the study variables at T1. Moreover, we had a relatively large dropout, which is partly in line with previous studies and may reflect the nature of the disorder [26, 53]. Since the main analysis and the sensitivity analysis of completers showed similar results, our findings appear to 
be valid and not confounded by internal dropouts. Furthermore, the psychoeducational control intervention had fewer sessions than the SSTG, making time a possible confounding factor in this study. However, since a few sessions of psychoeducation are recommended as an intervention for youths with ADHD [11], this was considered an appropriate control condition. The use of a non-active control group would have enabled us to draw firmer conclusions about absolute treatment effects; at the same time, from a clinical perspective, it was considered advantageous that all participants were offered an intervention, especially given the longitudinal design. Moreover, the sessions of the psychoeducational control intervention were not recorded and the risk of some treatment contamination cannot be completely ruled out. However, the procedure included several steps to strengthen treatment fidelity, including continuous education in the method, supervision and guidance, information to stick strictly to the manual, and the use of two therapists in each group. In addition, the number of group sessions delivered was registered for all groups, confirming that the participants did not receive more sessions than were included in the manual.

Since neither parents nor adolescents were blinded to the intervention, their expectations of each intervention may have biased their ratings. The addition of a more objective evaluation of the outcomes, e.g., by a clinician blinded to the treatment conditions, could have strengthened the conclusions. Considering the focus of the SSTG, the inclusion of a validated measure that more directly assesses emotional dysregulation would also have been warranted. Lastly, the characteristics of the sample might limit the generalisability of the findings in this study. A majority of this sample had an ongoing pharmacological treatment for ADHD, limiting the generalisability to non-medicated patients. Further, this sample included patients who were categorised as unspecified ADHD (i.e., did not fulfil criteria for any of the main presentations), and it is possible that there was limited room for further improvement for these adolescents. Despite this, the ADHD symptom ratings among our participants largely corresponded to the values shown in previous validation studies of the ASRS-A in a clinical population of Swedish adolescents with ADHD $[32,33]$. Two thirds of the sample reported symptoms of psychiatric comorbidity, and more than one third had psychopharmacological treatment other than ADHD medication. Although there were no group differences regarding these factors at baseline, potential changes of psychopharmacological treatment other than ADHD medication could have influenced the outcomes. Hence, it is a limitation that this factor was not included in the analyses. Moreover, a majority of the participants were girls $(64 \%)$, which does not correspond to the gender distribution of ADHD [1]. This might reflect a self-selection bias; a similar gender distribution has also been reported in previous evaluations of the SSTG for adults with ADHD $[24,25]$. However, previous research on psychosocial treatment for childhood ADHD have shown that gender does not seem to have a decisive role in treatment outcomes [14, 54]. Although we know that young individuals with ADHD in Sweden are more likely to have separated parents with lower education [55] and that the CAP units involved in this study have large uptake areas with patients from both rural and urban settings, the lack of information about socioeconomic status and treatment history for this particular sample was a limitation.

The main strength of the study was the RCT design, which decreased the risk for systematic differences and confounders. The multi-centre study within a clinical context increased ecological validity, and the longitudinal design enabled us to evaluate the persistence of the results. The use of both self-reports and parental reports contributed to a broader perspective on the outcomes. Results for all outcome measures have been presented in this paper, to avoid reporting bias [56].

In conclusion, the SSTG was perceived as helpful and seems to be acceptable for adolescents with ADHD in a clinical context. However, the treatment was not proved to be more effective or more acceptable than the psychoeducational control intervention. Though our findings indicate that the SSTG should not be recommended as part of the standard care for all adolescents with ADHD, more research is needed to explore if this treatment might be more beneficial for certain subgroups among patients with ADHD. In addition, further age adaptions of the SSTG, such as involvement of parents and more extensive practice, should be considered.

Supplementary Information The online version of this article (https:// doi.org/10.1007/s00787-021-01753-2) contains supplementary material, which is available to authorized users.

Acknowledgement We are grateful to all the families who participated in this study and to the child and adolescent psychiatric units for their contributions. The authors also thank Hans Arinell, Peter Csatlos, Anna Oremark, Elina Arn and Sofia Lantz for their valuable contribution to the work presented in this study. This research was financially supported by funds from the Uppsala University Hospital Research Fund (ALF), Uppsala County Council's Funds for Clinical Research, Uppsala-Örebro Regional Research Council, The Sven Jerring foundation, The foundation in memory of professor Bror Gadelius, Queen Silvia's Jubilee Fund and from the Foundation Sunnerdahls Disability Fund. The funders have no influence over the design, data collection, analysis, interpretation or in writing the manuscript of this study.

Funding Open access funding provided by Uppsala University.

Availability of data and materials Consent for data sharing outside the research team was not obtained. However, reasonable requests for patient-level data should be made to the corresponding author (JI) and will be considered after discussion with the ethical board. Relevant data is included in the manuscript. 


\section{Declarations}

Conflict of interest The authors declare that they have no conflict of interest.

Ethical approval The study is approved by the Regional Ethical Review Board, situated in Uppsala, Dnr 2015/257/1-4 and have therefore been performed in accordance with the ethical standards laid down in the 1964 Declaration of Helsinki and its later amendments.

Informed consent Before final inclusion, participants and their parents provided written informed consent.

Open Access This article is licensed under a Creative Commons Attribution 4.0 International License, which permits use, sharing, adaptation, distribution and reproduction in any medium or format, as long as you give appropriate credit to the original author(s) and the source, provide a link to the Creative Commons licence, and indicate if changes were made. The images or other third party material in this article are included in the article's Creative Commons licence, unless indicated otherwise in a credit line to the material. If material is not included in the article's Creative Commons licence and your intended use is not permitted by statutory regulation or exceeds the permitted use, you will need to obtain permission directly from the copyright holder. To view a copy of this licence, visit http://creativecommons.org/licenses/by/4.0/.

\section{References}

1. American Psychiatric Association (2013) Diagnostic and statistical manual of mental disorders, 5th edn. American Psychiatric Association, Arlington

2. Barkley R, Anastopoulos A, Guevremont D, Fletcher K (1991) Adolescents with ADHD: patterns of behavioral adjustment, academic functioning, and treatment utilization. J Am Acad Child Adolesc Psychiatry 30:752-761

3. Kent KM, Pelham WE, Molina BSG et al (2011) The academic experience of male high school students with ADHD. J Abnorm Child Psychol 39:451-462

4. Sibley MH, Evans SW, Serpell ZN (2010) Social cognition and interpersonal impairment in young adolescents with ADHD. J Psychopathol Behav Assess 32:193-202

5. Barkley RA (2006) Attention-deficit/hyperactivity disorder: a handbook for diagnosis and treatment, 3rd edn. Guilford Press, New York

6. Wehmeier PM, Schacht A, Barkley RA (2010) Social and emotional impairment in children and adolescents with ADHD and the impact on quality of life. J Adolesc Health 4:209-217

7. Bunford N, Evans SW, Langberg JM (2018) Emotion dysregulation is associated with social impairment among young adolescents with ADHD. J Atten Disord 22:66-82

8. Bunford N, Evans SW, Wymbs F (2015) ADHD and emotion dysregulation among children and adolescents. Clin Child Fam Psychol Rev 18:185-217

9. Smalley SL, McGough JJ, Moilanen IK et al (2007) Prevalence and psychiatric comorbidity of attention-deficit/hyperactivity disorder in an adolescent finnish population. J Am Acad Child Adolesc Psychiatry 46:1575-1583

10. Lee YC, Yang HJ, Chen VCH, Lee WT, Teng MJ, Lin CH, Gossop M (2016) Meta-analysis of quality of life in children and adolescents with ADHD: By both parent proxy-report and child selfreport using PedsQL ${ }^{\mathrm{TM}}$. Res Dev Disabil 51:160-172
11. National Institute for Health and Care Excellence (NICE) (2019) Attention deficit hyperactivity disorder: diagnosis and management. NICE guideline [NG87]. https://www.nice.org.uk/guidance/ ng87. Accessed August 62020

12. Chan E, Fogler JM, Hammerness PG (2016) Treatment of attention-deficit/hyperactivity disorder in adolescents: a systematic review. JAMA 315:1997-2008

13. Schoenfelder EN, Sasser T (2016) Skills versus pills: psychosocial treatments for ADHD in childhood and adolescence. Pediatr Ann 45:e367-e372

14. Vidal R, Castells J, Richarte V et al (2015) Group therapy for adolescents with attention-deficit/ hyperactivity disorder: a randomized controlled trial. J Am Acad Child Adolesc Psychiatry $54: 275-282$

15. Sprich SE, Safren SA, Finkelstein D, Remmert JE, Hammerness P (2016) A randomized controlled trial of cognitive behavioral therapy for ADHD in medication-treated adolescents. J child psychol psychiatry 57:1218-1226

16. Franke B, Michelini G, Asherson P et al (2018) Live fast, die young? A review on the developmental trajectories of ADHD across the lifespan. Eur Neuropsychopharmacol 28:1059-1088

17. Stern A, Agnew-Blais JC, Danese A et al (2020) Associations between ADHD and emotional problems from childhood to young adulthood: a longitudinal genetically sensitive study. J child psychol psychiatry

18. MacPherson HA, Cheavens JS, Fristad MA (2013) Dialectical behavior therapy for adolescents: theory, treatment adaptations, and empirical outcomes. Clin Child Fam Psychol Rev $16: 1659-1680$

19. Linehan MM (1993) Cognitive-behavioral treatment of borderline personality disorder. The Guildford Press, New York

20. Philipsen A, Feige B, Hesslinger B et al (2009) Borderline typical symptoms in adult patients with attention deficit/hyperactivity disorder. ADHD Attention Deficit and Hyperactivity Disorders $1: 11-18$

21. Cairncross M, Miller CJ (2020) The effectiveness of mindfulnessbased therapies for ADHD: a meta-analytic review. J Atten Disord 24:627-643

22. Hesslinger B, van Elst LT, Nyberg E, Dykierek P, Richter H, Berner M, Ebert D (2002) Psychotherapy of attention deficit hyperactivity disorder in adults. Eur Arch Psychiatry Clin Neurosci 252:177-184

23. Philipsen A, Richter H, Peters J et al (2007) Structured group psychotherapy in adults with attention deficit hyperactivity disorder: results of an open multicentre study. J Nerv Ment Dis 195:1013-1019

24. Morgensterns E, Alfredsson J, Hirvikoski T (2016) Structured skills training for adults with ADHD in an outpatient psychiatric context: an open feasibility trial. ADHD Attention Deficit Hyperact Disord 8:101-111

25. Hirvikoski T, Waaler E, Alfredsson J et al (2011) Reduced ADHD-symptoms in adults with ADHD after structured skills training group: results from a randomized controlled trial. Behav Res Ther 49:175-185

26. Philipsen A, Jans T, Graf E et al (2015) Effects of group psychotherapy, individual counseling, methylphenidate, and placebo in the treatment of adult attention-deficit/hyperactivity disorder: a randomized clinical trial. JAMA Psychiatry 72:1199-1210

27. Meyer J, Ramklint M, Hallerbäck MU, Lööf M, Isaksson J (2019) Evaluation of a structured skills training group for adolescents with attention deficit/hyperactivity disorder (ADHD)-study protocol of a randomised controlled trial. BMC Psychiatry 19:171

28. World Health O (1992) The ICD-10 classification of mental and behavioural disorders: clinical descriptions and diagnostic guidelines. WHO, Geneva 
29. Sheehan DV, Sheehan KH, Shytle RD et al (2010) Reliability and validity of the Mini International Neuropsychiatric Interview for Children and Adolescents (MINI-KID). J Clin Psychiatry 71:313-326

30. Hesslinger B, Philipsen A, Richter H (2004) Psychotherapie der ADHS im Erwachsenenalter: ein Arbeitsbuch. Hogrefe Verlag, Goettigen

31. Hesslinger B, Philipsen A, Richter H (2010) Psychotherapie der ADHS im Erwachsenenalter: Ein Arbeitsbuch/Psykoterapi för vuxna med ADHD-En arbetsbok. Swedish version: Hirvikoski T, Pihlgren C, Waaler E, Larsson M, Alfredsson J. Hogrefe Psykologiförlaget, Stockholm

32. Sonnby K, Skordas K, Olofsdotter S, Vadlin S, Nilsson KW, Ramklint M (2015) Validation of the World Health Organization adult ADHD self-report scale for adolescents. Nord J Psychiatry 69:216-223

33. Sjölander L, Vadlin S, Olofsdotter S, Sonnby K (2016) Validation of the parent version of the World Health Organization Adult ADHD Self-Report Scale for adolescents. Nord J Psychiatry 70:255-261

34. Whiteside SP (2009) Adapting the Sheehan disability scale to assess child and parent impairment related to childhood anxiety disorders. J Clin Child Adolesc Psychol 38:721-730

35. Ivarsson B, Malm U, Lindström L, Norlander T (2010) The selfassessment Global Quality of Life scale: reliability and construct validity. Int J Psychiatry Clin Pract 14:287-297

36. Baer RA, Smith GT, Lykins E et al (2008) Construct validity of the five facet mindfulness questionnaire in meditating and nonmeditating samples. Assessment 15:329-342

37. Lilja JL, Frodi-Lundgren A, Hanse JJ et al (2011) Five facets mindfulness questionnaire-reliability and factor structure: a Swedish version. Cogn behav ther 40:291-303

38. Goodman R (1997) The strengths and difficulties questionnaire: a research note. J child psychol psychiatry 38:581-586

39. Malmberg M, Rydell AM, Smedje H (2003) Validity of the Swedish version of the Strengths and Difficulties Questionnaire (SDQSwe). Nord J Psychiatry 57:357-363

40. He JP, Burstein M, Schmitz A, Merikangas KR (2013) The Strengths and Difficulties Questionnaire (SDQ): the factor structure and scale validation in US adolescents. J Abnorm Child Psychol 41:583-595

41. Zigmond AS, Snaith RP (1983) The hospital anxiety and depression scale. Acta Psychiatr Scand 67:361-370

42. White D, Leach C, Sims R, Atkinson M, Cottrell D (1999) Validation of the hospital anxiety and depression scale for use with adolescents. Br J Psychiatry 175:452-454
43. Lindblad F, Backman L, Åkerstedt T (2008) Immigrant girls perceive less stress. Acta paediatr 97:889-893

44. Nordin M, Åkerstedt T, Nordin S (2013) Psychometric evaluation and normative data for the Karolinska Sleep Questionnaire. Sleep Biol Rhythms 11:216-226

45. Ghasemi A, Zahediasl S (2012) Normality tests for statistical analysis: a guide for non-statisticians. Int J endocrinol metab 10:486

46. West BT (2009) Analyzing longitudinal data with the linear mixed models procedure in SPSS. Eval Health Prof 32:207-228

47. Boyer BE, Geurts HM, Prins PJ, Van der Oord S (2015) Two novel CBTs for adolescents with ADHD: the value of planning skills. Eur Child Adolesc Psychiatry 24:1075-1090

48. Wampold BE (2015) How important are the common factors in psychotherapy? An update. World Psychiatry 14:270-277

49. Karlsson P, Bergmark A (2015) Compared with what? An analysis of control-group types in Cochrane and Campbell reviews of psychosocial treatment efficacy with substance use disorders. Addiction 110:420-428

50. DuPaul GJ, Evans SW, Mautone JA, Owens JS, Power TJ (2020) Future Directions for Psychosocial Interventions for Children and Adolescents with ADHD. J Clin Child Adolesc Psychol 49:134-145

51. Evans SW, Owens JS, Wymbs BT, Ray AR (2018) Evidence-based psychosocial treatments for children and adolescents with attention deficit/hyperactivity disorder. J Clin Child Adolesc Psychol 47:157-198

52. Dahl V, Ramakrishnan A, Spears AP, Jorge A, Lu J, Bigio NA, Chacko A (2020) Psychoeducation interventions for parents and teachers of children and adolescents with ADHD: a systematic review of the literature. J Dev Phys Disabil 32:257-292

53. Zetterqvist $\mathrm{J}$, Asherson $\mathrm{P}$, Halldner L, Långström $\mathrm{N}$, Larsson $\mathrm{H}$ (2013) Stimulant and non-stimulant attention deficit/hyperactivity disorder drug use: total population study of trends and discontinuation patterns 2006-2009. Acta Psychiatr Scand 128:70-77

54. Hinshaw SP (2007) Moderators and mediators of treatment outcome for youth with ADHD: Understanding for whom and how interventions work. J Pediatr Psychol 32:664-675

55. Björkenstam E, Björkenstam C, Jablonska B, Kosidou K (2018) Cumulative exposure to childhood adversity, and treated attention deficit/hyperactivity disorder: a cohort study of 543650 adolescents and young adults in Sweden. Psychol Med 48:498-507

56. The Cochrane Collaboration (2019) Cochrane Handbook for Systematic Reviews of Interventions. https://training.cochrane.org/ handbook/current/chaper-08. Accessed August 62020 